Psychological Topics, 29 (2020), 1, 167-190

Original Scientific Paper

UDC: 159.942 .072

doi:https://doi.org/10.31820/pt.29.1.10

\title{
Cross-Cultural and Gender Measurement Invariance of the Intrapersonal and Interpersonal Emotional Competence Questionnaire
}

\author{
Andreja Avsec - University of Ljubljana, Ljubljana, Slovenia \\ Irina Belasheva - North-Caucasus Federal University, Stavropol, Russia \\ Jiri Cenek - Mendel University, Brno, Czech Republic \\ Azizuddin Khan - Indian Institute of Technology, Bombay, India \\ Tamara Mohorić - University of Rijeka, Rijeka, Croatia \\ Vladimir Takšić - University of Rijeka, Rijeka, Croatia
}

Gaja Zager Kocjan - University of Ljubljana, Ljubljana, Slovenia

\begin{abstract}
The Intrapersonal and Interpersonal Emotional Competence Questionnaire (IIECQ) was developed from the Emotional Skills and Competence Questionnaire, addressing some of its content issues. Measurement invariance of the two-factor IIECQ model (interpersonal and intrapersonal emotional competence factors) was examined across countries and gender groups using a sample of 998 students from five different countries (Slovenia, Russia, Croatia, India, and the Czech Republic). Our results supported partial scalar invariance of the IIECQ across countries with three items having varying intercepts in different countries. Scalar invariance was fully confirmed across gender groups. Latent means for the two IIECQ factors were compared between the five countries and the two gender groups. While men and women reported similar levels of intrapersonal and interpersonal emotional competences, significant differences were observed between some of the countries. To assess the construct validity of the IIECQ, correlations were examined between the IIECQ subscale scores and the measures of emotion regulation, personality, and well-being. In general, correlations were low to moderate and in accordance with expectations, showing adequate convergent validity of the new scales. Overall, the IIECQ represents a psychometrically sound measure of the intrapersonal and interpersonal emotional competences, which are measured in the same way across the five countries examined as well as across genders.
\end{abstract}

Keywords: emotional intelligence, measurement invariance, The Intrapersonal and Interpersonal Emotional Competences Questionnaire, cross-cultural differences

Andreja Avsec, Department of Psychology, University of Ljubljana, Askerceva 2, 1000 Ljubljana, Slovenia. E-mail: andreja.avsec@ff.uni-lj.si

Authors Note:

The authors acknowledge the financial support from the Slovenian Research Agency (research core funding No. P5-0110) 


\section{Introduction}

The construct of emotional intelligence (Salovey \& Mayer, 1990) is almost 90 years younger compared to that of general intelligence (Binet, 1905/1916), so the empirical results regarding emotional intelligence have been aggregated for only 30 years so far. Still, the researchers have plenty of options to measure the construct. Lack of agreement among researchers regarding the constitutive components of emotional intelligence led to a wide array of different emotional intelligence measures of both maximum and typical performance (O'Connor, Hill, Kaya, \& Martin, 2019; Petrides, Pita, \& Kokkinaki, 2007). Among typical performance measures, questionnaires have been developed which incorporate almost all aspects of one's personality (mixed models; e.g., Bar-On, 2002; Goleman, 1995; Saklofske, Austin, \& Minski, 2003). On the other side, measures focused on narrow abilities directly related to what an individual does with her emotions in typical settings, have also been proposed (e.g., MacCann \& Roberts, 2008).

The Emotional Skills and Competences Questionnaire (ESCQ; Takšić, 1998, 2001 ) is one of the ability focused self-report measures. Originally, it was developed in a Croatian setting using the theoretical framework of the emotional intelligence model (Mayer \& Salovey, 1997). The Mayer-Salovey model was updated recently and some specific abilities were added (Mayer, Caruso, \& Salovey, 2016), but the four-branch (perception, understanding, facilitation, regulation) structure remained although the results (Legree et al., 2014; MacCann, Joseph, Newman, \& Roberts, 2014) usually did not confirm emotional facilitation as a separate branch. The items of the ESCQ have been generated by a standard procedure: 300 items were generated based on 16 emotional abilities from the Mayer-Salovey's model (Mayer \& Salovey, 1997) or added from already used scales (Averill \& Thomas-Knowles, 1991; Mayer, Caruso, Ziegler, \& Dryden, 1989; Mayer \& Stevens, 1994; Salovey, Mayer, Goldman, Turvey, \& Palfai, 1995). Exploratory factor analysis suggested 16 scales (encompassing 136 items), later also a three-factor structure, leading to the development of a shorter 45 -item questionnaire measuring the abilities to perceive and understand emotions (PU), express and label emotions (EL), and manage and regulate emotions (MR). The three-factor structure of the questionnaire was confirmed in many studies (Faria et al., 2006; Takšić, 2005; Takšić, Mohorić, \& Holmström, 2018). The questionnaire has been translated into English and the English version into several languages: Portuguese (Faria \& Lima Santos, 2005), Spanish (Extremera \& Fernández-Berrocal, 2005; Mikulić, 2008), Swedish (Molander, Holmström, \& Jansson, 2005), Finnish (Räty, 2005), Japanese (Toyota, Morita, \& Takšić, 2007), French (Lapierre, 2008), and Chinese-Mandarin (Xu, 2008), using the back-translation technique (van de Vijver \& Hambleton, 1996). Translation into Slovene language (Avsec, 2005) was performed directly from Croatian. 
In an attempt to estimate convergent and divergent validity, the ESCQ subscales were compared to scores from personality scales and other scales measuring similar constructs. Among the big five personality dimensions, extraversion and openness correlated most strongly with the ESCQ scales. The highest correlations were found with the MR subscale and the lowest with the PU subscale (Avsec, Takšić, \& Mohorić, 2009). The correlations were reasonably low to conclude that the ESCQ has divergent validity from the big five personality traits.

The ESCQ also showed strong positive correlations with the maintenance of positive mood (Takšić, 2002), and subjective well-being was established as the main criterion for concurrent and incremental validity of the ESCQ (Takšić, 1998, 2002). It seems reasonable to expect that abilities regarding perception, understanding, managing, and using emotions to reach desired goals help to achieve better wellbeing (Sánchez-Álvarez, Extremera, \& Fernández-Berrocal, 2015). Although mixed models integrate well-being into the construct of EI (e.g., Petrides, Sangareau, Furnham, \& Frederickson, 2006), the self-reported abilities models of EI usually treat EI as a precursor to feelings associated with well-being (Mayer \& Salovey, 1995; see also Avsec, Masnec, \& Komidar, 2009).

Twenty years after the 45-item ESCQ had been introduced, a need for a shorter and revised version of the questionnaire emerged to overcome some difficulties and inconsistencies from the original version. In the original item poll, the 300 items were related to all 16 specific abilities from the Mayer and Salovey's model. However, the three-factor structure underlying 45 items that were included in the ESCQ, was not ideally aligned to this theoretical model (Takšić, Mohorić, \& Duran, 2009) and did not comprehend evenly all 16 emotional abilities.

Another problematic issue we tried to address in a new questionnaire is a different share of items in each of the three ESCQ subscales that are related to one's own emotions or other person's emotions. Although this distinction was not hypothesized by Mayer and Salovey (1997), most of the self-reported emotional intelligence instruments differentiate between abilities related to own and other's emotions, even if this is not always explicitly reflected in the naming of the subscales. The distinction between self- and other-related emotional competences is also aligned with Gardner's theoretic conceptualization of multiple intelligences (Gardner, 1983). In the 45-item version of the ESCQ, only one of the 16 items from the PU subscale is related to one's own emotional abilities, whereas all but two items from the EL and all but one from the MR are related to individual's own emotional abilities. It seems that would be more appropriate to rename the EL scale as intrapersonal and PU as interpersonal emotional competence scales.

Additionally, in the new questionnaire we tried to unify the level of specificity of the emotions expressed in the items from different subscales. In the 45-item version, nine items from the PU subscale incorporate one specific emotion (e.g., pride, sorrow, angry...). On the other hand, in the EL subscale only one item includes a specific emotion, whereas all other items refer to emotions in general. Also, the 
MR subscale includes only emotions in general or positive and negative emotions, with no specific emotions mentioned.

In the 45-item version of the ESCQ, the MR subscale has the lowest internal consistency and exhibits problems with construct validity (Takšić et al., 2009). It seems that a variety of emotional abilities forms this scale; from 16 items, five are related to an ability to maintain a positive mood, whereas others refer to a determination to perform duties and assignments, doing things with a positive attitude, to ability to accept one's own feelings, persuade friends, etc. For this reason, all of the items from the MR subscale were omitted from the new questionnaire.

In the new questionnaire, we tried to address all the above-mentioned shortcomings of the 45-item version of the ESCQ. We omitted the items from the PU subscale that were related to specific emotions and we simplified one item from this subscale. On the other hand, we also tried to shorten the EL subscale, so that the items with the lowest item-total correlation were omitted (Takšić, Bradić, \& Žauhar, 2013). Altogether, twelve items remained of which six were related to perceiving and understanding one's own emotions and six to perceiving and understanding other's emotions (Table 1).

Table 1

Items from the Revised Version of the ESCQ

\begin{tabular}{|c|c|}
\hline Intrapersonal skills and competences & Interpersonal skills and competences \\
\hline $\begin{array}{l}\text { 1. Putting my feelings and emotions into } \\
\text { words comes easily to me. (2) }\end{array}$ & $\begin{array}{l}\text { 7. When I see how someone feels, I usually } \\
\text { know what has happened to him. (14) }\end{array}$ \\
\hline $\begin{array}{l}\text { 2. I am capable to list the emotions that I } \\
\text { am currently experiencing. (17) }\end{array}$ & $\begin{array}{l}\text { 8. If I observe a person in the presence of } \\
\text { others, I can determine precisely her or } \\
\text { his/her emotions. }(25)\end{array}$ \\
\hline $\begin{array}{l}\text { 3. I can recognize most of my feelings. } \\
\text { (22) }\end{array}$ & $\begin{array}{l}\text { 9. I am able to tell somebody's feelings by } \\
\text { the expression on his/her face. (34) }\end{array}$ \\
\hline $\begin{array}{l}\text { 4. I am capable to describe my present } \\
\text { emotional state. }(23)\end{array}$ & $\begin{array}{l}\text { 10. I notice when somebody tries to hide } \\
\text { his/her bad mood. (36) }\end{array}$ \\
\hline $\begin{array}{l}\text { 5. I can easily name most of my feelings. } \\
\text { (43) }\end{array}$ & $\begin{array}{l}\text { 11. I notice when somebody tries to hide } \\
\text { his/her real feelings. (38) }\end{array}$ \\
\hline $\begin{array}{l}\text { 6. I am able to understand how I feel. } \\
\text { (new) }\end{array}$ & $\begin{array}{l}\text { 12. I notice when somebody's behaviour } \\
\text { varies considerably from his/her mood. } \\
\text { (42) }\end{array}$ \\
\hline
\end{tabular}

Note. The numbers in brackets indicate the number of the item in the longer version of the ESCQ.

In the present study, psychometric characteristics of the Intrapersonal and Interpersonal Emotional Competence Questionnaire were examined and measurement invariance of the scale was investigated across genders and five countries: Croatia, Slovenia, India, Russia, and the Czech Republic. Also, latent 
Avsec, A., Belasheva, I., Cenek, J., Khan, A., Mohorić, T., Takšić, V., Zager Kocjan, G.: Measurement Invariance of the ESCQ-R

means of the two emotional intelligence factors were compared between countries and gender groups. Finally, correlations were computed between IIECQ subscales and measures of personality and well-being to examine the convergent validity of the IIECQ.

\section{Method}

\section{Participants}

The study included a convenience sample of Slovene, Croatian, Czech, Russian, and Indian students. Sample sizes with gender and age structure are presented in Table 2.

Table 2

Sample Structure across Countries: Age, Proportion of Women and Language of the Assessment Instruments

\begin{tabular}{lccccc}
\hline & $N$ & \multicolumn{2}{c}{ Age } & \multirow{2}{*}{$\begin{array}{c}\text { Female } \\
\%\end{array}$} & Language \\
\cline { 3 - 4 } & & $M$ & $S D$ & & \\
\hline Croatia & 202 & 21.94 & 2.35 & 75.2 & Croatian \\
Czech Republic & 149 & 22.68 & 2.09 & 58.4 & Czech \\
India & 145 & 21.98 & 2.91 & 44.8 & English \\
Russia & 289 & 19.17 & 1.21 & 66.1 & Russian \\
Slovenia & 213 & 23.03 & 2.52 & 73.2 & Slovene \\
Total & 998 & 21.49 & 2.67 & 65.2 & \\
\hline
\end{tabular}

\section{Measures}

The Intrapersonal and Interpersonal Emotional Competence Questionnaire (IIECQ) is composed of two subscales measuring Intrapersonal emotional competences (six items) and Interpersonal emotional competences (six items). Participants are asked to rate on a 5-point scale ranging from 1 (never) to 5 (always) how often they manifest specific behaviours.

The Emotion Regulation Questionnaire (ERQ, Gross \& John, 2003) consists of 10 items covering two factors: Cognitive Reappraisal (six items) and Expressive Suppression (four items). Items are rated on a 7-point Likert scale ranging from 1 (strongly disagree) to 7 (strongly agree). Metric characteristics were examined in different cultures (e.g., Haga, Kraft, \& Corby, 2009; Melka, Lancaster, Bryant, \& Rodriguez, 2011; Rice, Treeby, Gersh, Ogrodniczuk, \& Kealy, 2018). Alpha coefficients of internal consistency for the present samples are presented in the appendix (Table A1). 
The Mental Health Continuum-Short Form (MHC-SF; Keyes, 2005) consists of 14 items aimed at measuring three components of well-being: emotional (three items), social (five items), and psychological (six items). Participants are asked to rate how often they felt a certain way during the past month, on a 6-point scale ranging from 0 (never) to 6 (every day). A cross-cultural study with samples from 38 nations (Żemojtel et al., 2018) confirmed the invariance of the proposed three-factor structure with one higher-order general factor. Alpha coefficients of internal consistency from our samples are presented in the appendix (Table A1).

A short version of the Big Five Inventory (BFI-K; Kovaleva, Beierlein, Kemper, \& Rammstedt, 2013) measures five basic personality traits: Extraversion, Agreeableness, Conscientiousness, Neuroticism, and Openness to Experience. The 21-item measure utilizes a scale ranging from 1 (strongly disagree) to 5 (strongly agree). The five-factor structure was validated using ESEM (Kovaleva et al., 2013). Alpha coefficients of internal consistency for the present samples are presented in the appendix (Table A1).

All instruments but IIECQ were originally constructed in the English language. For the purpose of this study, the already existing Slovene and Croatian adaptions of the questionnaires were used. For other languages, translations and back translations were made for all the scales.

\section{Procedure}

Participants filled out the questionnaires over the web, using a one-click survey tool (www.1 ka.si). All participants answered the questions in their native language. The exception were Indians, who despite having an opportunity to fill out the questionnaires in Hindi, decided to fill them out in English (only one person answered in Hindi, so we excluded this one from the analysis). The participants were invited to participate via social networks of the main researchers from each country. In Slovenia and Croatia, the participants had an opportunity to find out their individual results.

\section{Statistical Analysis}

Confirmatory factor analysis (CFA) and multigroup CFA (MG-CFA) were performed in Mplus version 8.2 (Muthén \& Muthén, 1998-2018). Baseline factor structure models of the IIECQ were first established for each country, with a theoretically presupposed two-factor model fitted to the data. To identify the models, the factor variances were set to 1 so that all item loadings could be estimated. The robust maximum likelihood method (MLR) was used to estimate the models. Measurement invariance of the IIECQ across country and gender groups was examined using MG-CFA. First, the configural invariance model was tested, specifying the same factor structure for all groups. Next, the fit of the metric 
invariance model was examined with factor loadings held equivalent across groups. Finally, scalar invariance model was assessed with factor loadings and item intercepts constrained to equality across all groups.

Model fit was evaluated using the Satorra-Bentler scaled chi-square test statistic $\left(\mathrm{SB} \chi^{2}\right)$, the root-mean-square error of approximation (RMSEA), and the comparative fit index (CFI). RMSEA values lower than .08 are usually considered as acceptable model fit and values below .05 are considered as good model fit (Browne \& Cudeck, 1993). CFI values below 90 indicate poor model fit (Bentler, 1990) and values above .95 indicate good model fit (Hu \& Bentler, 1999). Chen's recommendations (2007) for comparing CFI and RMSEA values were followed to evaluate the fit of the increasingly stringent models (i.e., $\Delta \mathrm{CFI} \leq .010$ and $\triangle \mathrm{RMSEA} \leq .015$ ). If metric or scalar invariance would not be achieved, we planned to resort to modification indices and remove some of the equality restrictions to establish partial measurement invariance (e.g., Byrne, Shavelson, \& Muthén, 1989).

To compare the latent means across countries and gender groups, latent means for the two factors were set to zero in one of the countries and gender groups, respectively, and freely estimated in the rest of the groups. The significance of the differences in the latent means with the reference group was examined using $Z$-tests, and the Model constraint command in Mplus was used to compare all other pairs of groups. Construct validity of the IIECQ was examined through Pearson's correlations with the measures of emotion regulation, basic personality traits, and well-being, separately for each country and gender group.

\section{Results and Discussion}

Descriptive statistics of the twelve IIECQ items and the two subscale scores across countries and gender groups are presented in Table A2 in the Appendix. Table A3 in the Appendix contains corrected item-total correlations for all the items and alpha reliability coefficients across groups.

\section{Confirmatory Factor Analysis and Measurement Invariance across Countries}

To establish well-fitting baseline models across countries, the hypothesized two-factor model was first tested for each country separately (Byrne, 2008). According to the obtained fit indices, the model provided poor fit to the data in the Slovene, Indian, and Czech samples (models S1, I1, and CZ1). The fit was acceptable in the Russian sample (model R1) and it was marginally acceptable in the Croatian sample (model C1; Table 3). A review of the modification indices, which is a common practice to improve fit statistics (Byrne, 2013), revealed that the fit of the initial models could be increased by freely estimating correlations between some of the item residuals for each country. Specifically, in the Slovene and Croatian samples 
high modification index was obtained for the correlation between the residuals of the items 8 (If I observe a person in the presence of others, I can determine precisely his/her emotions.) and 9 (I am able to tell somebody's feelings by the expression on his/herface.). These items overlap highly in their content (i.e., the ability to recognize other persons' feelings) and both belong to the interpersonal IIECQ subscale. Allowing their error terms to correlate significantly improved the fit of the two-factor model in the Slovene and Croatian samples and led to an acceptable fit of the model in both countries (models S2 and C2). In the Russian sample, a large modification index was associated with the correlation between the residuals of the items 8 and 11 (I notice when somebody tries to hide his/her real feelings.) that are again both part of the interpersonal IIECQ subscale and are related to accurate detection of emotions in other people. After this error term was freely estimated, the fit was significantly enhanced compared to the original model, with fit indices suggesting a good fit of the model to the data (model R2). In the Indian sample, an inspection of the modification indices revealed highly correlated residuals of the items 2 (I am capable to list the emotions that I am currently experiencing.) and 3 (I am capable to describe my present emotional state.) that both belong to the intrapersonal IIECQ subscale and refer to the ability to describe one's inner emotional state. Freely estimating the correlation between their residuals improved the fit of the model, but the obtained fit indices still suggested only marginally acceptable fit to the data (model I2). Further inspection of the modification indices revealed that the fit could be additionally improved by freely estimating the correlation between the residuals of the items 7 (When I see how someone feels, I usually know what has happened to him.) and 8, both coming from the interpersonal IIECQ subscale and referring to the ability to explain how other people feel and why. This modification in the model resulted in a significantly improved and acceptable fit of the two-factor model to the Indian data (model I3). Finally, in the Czech sample, the highest modification index was also related to the correlated residuals of the items 7 and 8 . After freely estimating this residual correlation the fit of the model was significantly improved, yet still poor (model CZ2). A further review of the modification indices showed a high correlation between the residuals of the items 8 and 11, already described above. Freely estimating this correlation led to an improved and acceptable fit of the model to the data (model CZ3). Table A2 in the Appendix presents factor loadings for the modified two-factor models and the McDonald's omega reliability coefficients for each country. 
Avsec, A., Belasheva, I., Cenek, J., Khan, A., Mohorić, T., Takšić, V., Zager Kocjan, G.: Measurement Invariance of the ESCQ-R

Table 3

Fit Statistics for the Two-Factor IIECQ Model for the Five Countries and the Comparison of the Configural, Metric, Scalar, and Partial Scalar Invariance Models by Country

\begin{tabular}{|c|c|c|c|c|c|c|c|c|c|}
\hline & \multicolumn{4}{|c|}{ Goodness-of-fit } & \multicolumn{5}{|c|}{ Model comparison } \\
\hline & $\mathrm{SB} \chi_{(d f)}^{2}$ & RMSEA & $90 \% \mathrm{CI}$ & CFI & $\begin{array}{c}\text { Ref. } \\
\text { model }\end{array}$ & $\Delta \mathrm{SB} \chi^{2}(d f)$ & $p$ & $\triangle$ RMSEA & $\Delta \mathrm{CFI}$ \\
\hline \multicolumn{10}{|c|}{ Two-factor models by country } \\
\hline S1: Slovenia & $135.393(53)$ & .085 & {$[.068, .103]$} & .913 & & & & & \\
\hline S2: Slovenia & $96.723(52)$ & .064 & {$[.043, .083]$} & .953 & $\mathrm{~S} 1$ & $45.870(1)$ & $<.001$ & .021 & .040 \\
\hline I1: India & $116.592(53)$ & .091 & {$[.069, .113]$} & .866 & & & & & \\
\hline I2: India & $94.430(52)$ & .075 & {$[.050, .099]$} & .911 & I1 & $16.428(1)$ & $<.001$ & .016 & .045 \\
\hline I3: India & $82.308(51)$ & .065 & {$[.037, .090]$} & .934 & $\mathrm{I} 2$ & $12.024(1)$ & .001 & .010 & .023 \\
\hline C1: Croatia & $117.943(53)$ & .078 & {$[.059, .097]$} & .928 & & & & & \\
\hline C2: Croatia & $95.810(52)$ & .065 & {$[.044, .085]$} & .951 & $\mathrm{C} 1$ & $32.837(1)$ & $<.001$ & .013 & .023 \\
\hline CR1: Czech Repub. & $131.323(53)$ & .100 & {$[.078, .121]$} & .853 & & & & & \\
\hline CR2: Czech Repub. & $107.392(52)$ & .085 & {$[.062, .107]$} & .896 & CR1 & $239.071(1)$ & $<.001$ & .015 & .043 \\
\hline CR3: Czech Repub. & $88.750(51)$ & .070 & {$[.045, .095]$} & .929 & $\mathrm{CR} 2$ & $60.916(1)$ & $<.001$ & .015 & .033 \\
\hline R1: Russia & $116.644(53)$ & .064 & {$[.049, .080]$} & .922 & & & & & \\
\hline R2: Russia & $85.903(52)$ & .047 & {$[.029, .065]$} & .958 & $\mathrm{R} 1$ & $35.922(1)$ & $<.001$ & .017 & .036 \\
\hline \multicolumn{10}{|c|}{ Measurement invariance across countries } \\
\hline CM1: Configural & $449.110(258)$ & .061 & {$[.051, .070]$} & .948 & & & & & \\
\hline CM2: Metric & $518.244(298)$ & .061 & {$[.052, .070]$} & .940 & CM1 & $69.107(40)$ & .003 & .000 & .008 \\
\hline CM3: Scalar & $684.852(388)$ & .072 & {$[.064, .079]$} & .905 & $\mathrm{CM} 2$ & $167.223(90)$ & $<.001$ & .011 & .035 \\
\hline CM3b: Partial scalar & $650.288(334)$ & .069 & {$[.061, .077]$} & .914 & $\mathrm{CM} 2$ & $142.725(36)$ & $<.001$ & .008 & .026 \\
\hline CM3c: Partial scalar & $616.921(330)$ & .066 & {$[.058, .074]$} & .922 & $\mathrm{CM} 2$ & $104.613(32)$ & $<.001$ & .005 & .018 \\
\hline CM3d: Partial scalar & $593.796(327)$ & .064 & {$[.056, .072]$} & .927 & $\mathrm{CM} 2$ & $78.869(29)$ & $<.001$ & .003 & .013 \\
\hline
\end{tabular}

Note. $\mathrm{SB} \chi^{2}=$ Satorra-Bentler Scaled Chi-Square; $d f=$ degrees of freedom; RMSEA = Root Mean Square Error of Approximation; $\mathrm{CI}=$ confidence interval $\mathrm{CFI}=\mathrm{Comparative} \mathrm{Fit} \mathrm{Index;} \mathrm{Ref.} \mathrm{model} \mathrm{=} \mathrm{reference} \mathrm{model;} \Delta \mathrm{SB} \chi^{2}, \Delta \mathrm{CFI}$, and $\triangle \mathrm{RMSEA}=$ change in fit indices between contiguous nested models.

The adequately fitting modified two-factor models of the five countries in which some of the error covariances were estimated freely (i.e., models S2, I3, C2, CR3, and R2) were used as baseline models and combined in a multiple-group model for measurement invariance testing. At this point, it is worth noting that baseline models are not required to be perfectly identical across the investigated groups (Byrne, 2008). The configural invariance model provided acceptable fit to the data (model CM1; Table 3) implying an equal factor structure of the IIECQ across the five countries. The metric invariance model with invariant factor loadings across countries fitted the data similarly well with acceptably low attenuation in model fit compared to the configural model (model CM2), as indicated by the $\triangle$ RMSEA and $\triangle$ CFI values (Chen, 2007). The fit of the scalar invariance model in which item intercepts were constrained across all countries was marginally acceptable and, according to Chen's criteria (2007), significantly worse compared to the less 
restrictive metric invariance model (model CM3). The inspection of the modification indices revealed that freely estimating the intercept of the item 5 should improve the model fit (Byrne et al., 1989). The fit of the partial scalar invariance model with the freely estimated intercept of the item 5 was still significantly worse compared to the metric model, considering the $\triangle \mathrm{CFI}$ value (model CM3b). Further inspection of the modification indices suggested that the intercept of the item 6 may not be invariant across countries. However, also after this intercept was estimated freely, the $\Delta$ CFI value suggested significantly worse fit compared to the metric invariance model (model CM3c). In line with the modification indices, the intercept of the item 1 was also estimated freely. The partial scalar invariance model with the intercepts of the items 1,5 , and 6 freely estimated, resulted in an acceptable fit to the data, and the attenuation in model fit compared to the metric invariance model was within the acceptable range (model CM3d). The three items, with varying intercepts, were all from the intrapersonal subscale (Putting my feelings and emotions into words comes easily to me. I can easily name most of my feelings. I am able to understand how I feel.). A possible reason for their non-invariance could be attributed to minor adaptations of their content, which occurred in some of the translations to make items sound idiomatic in the target language. According to the literature (Steenkamp \& Baumgartner, 1998), at least two invariant items are required per scale for a valid group comparison. Therefore, our results show that using the IIECQ interpersonal and intrapersonal emotional competences are measured in the same way across the five countries investigated, and that the IIECQ scores can be meaningfully compared between these countries.

\section{Confirmatory Factor Analysis and Measurement Invariance across Genders}

Measurement invariance was also examined across genders using the aggregated data from the five countries (Table 4). Well-fitting baseline two-factor models were first established for both genders. For the male group, the two-factor model provided marginally acceptable fit to the data (model M1). Modification indices were inspected revealing a large value for the previously discussed correlation between the residuals of the items 2 and 3 from the IIECQ intrapersonal subscale. The fit of the model with this residual covariance freely estimated was acceptable and significantly improved compared to the original model (model M2). For the female group, the fit of the two-factor model was poor (model F1). A large modification index was suggested for the correlation between the residuals of the items 10 (I notice when somebody tries to hide his/her bad mood.) and 11 from the IIECQ interpersonal subscale that both refer to noticing hidden feelings in other people. Freeing the covariance between the residuals of these two items resulted in an improved fit of the model to the data compared to the original model (model F2). However, a large modification index for the residual covariance between items 2 and 3 suggested that the fit of this model could be further enhanced by freely estimating one additional residual covariance (the same as in the male group). This modification 
Avsec, A., Belasheva, I., Cenek, J., Khan, A., Mohorić, T., Takšić, V., Zager Kocjan, G.: Measurement Invariance of the ESCQ-R

in the model resulted in an acceptable and significantly improved fit of the two-factor model to the data (model F3). Factor loadings for the modified two-factor models for the two genders and the McDonald's omega reliability coefficients can be found in Table A2 in the Appendix.

Table 4

Fit Statistics for the Two-Factor IIECQ Model for the Two Gender Groups and the Comparison of the Configural, Metric, and Scalar Invariance Models by Gender

\begin{tabular}{|c|c|c|c|c|c|c|c|c|c|}
\hline & \multicolumn{4}{|c|}{ Goodness-of-fit } & \multicolumn{5}{|c|}{ Model comparison } \\
\hline & $\mathrm{SB} \chi_{(d f)}^{2}$ & RMSEA & $90 \% \mathrm{CI}$ & CFI & $\begin{array}{c}\text { Ref. } \\
\text { model }\end{array}$ & $\Delta \mathrm{SB} \chi^{2}(d f)$ & $p$ & $\triangle \mathrm{RMSEA}$ & $\Delta \mathrm{CFI}$ \\
\hline \multicolumn{10}{|c|}{ Two-factor models by gender } \\
\hline M1: Male & $147.233(53)$ & .072 & {$[.058, .085]$} & .910 & & & & & \\
\hline M2: Male & $118.350(52)$ & .061 & {$[.046, .075]$} & .936 & M1 & $21.588(1)$ & $<.001$ & .011 & .026 \\
\hline F1: Female & $279.959(53)$ & .081 & {$[.072, .091]$} & .898 & & & & & \\
\hline F2: Female & $215.944(52)$ & .070 & {$[.060, .079]$} & .926 & $\mathrm{~F} 1$ & $87.376(1)$ & $<.001$ & .011 & .028 \\
\hline F3: Female & $188.442(51)$ & .064 & {$[.055, .074]$} & .938 & $\mathrm{~F} 2$ & $22.807(1)$ & $<.001$ & .006 & .012 \\
\hline \multicolumn{10}{|c|}{ Measurement invariance across gender } \\
\hline GM1: Configural & $307.280(103)$ & .063 & {$[.055, .071]$} & .937 & & & & & \\
\hline GM2: Metric & $315.054(113)$ & .060 & {$[.052, .068]$} & .938 & GM1 & $5.866(10)$ & .826 & -.003 & -.001 \\
\hline GM3: Scalar & $334.575(123)$ & .059 & {$[.051, .066]$} & .935 & GM2 & $17.613(10)$ & .062 & -.001 & .003 \\
\hline
\end{tabular}

The well-fitting modified models for the two gender groups in which the above mentioned residual covariances were estimated freely (i.e., models M2 and F3) were combined in a multiple-group model for measurement invariance testing. The configural invariance model for the two gender groups showed acceptable fit to the data (model GM1; Table 4). Even slightly better was the fit of a more restrictive metric invariance model (model GM2). Also, the scalar invariance model fitted the data acceptably well with no significant attenuation in fit statistics compared to the metric invariance model (model GM3). These findings suggest that the intrapersonal and interpersonal skills and competences are measured in the same way for both genders by the IIECQ.

\section{Latent Means Comparison}

Measurement invariance across groups is a necessary precondition for the examination of group differences. Hence, our next step was to compare latent means between the five countries and the two gender groups, respectively. Latent means for the two IIECQ factors were set to zero in the Slovene sample and freely estimated in the other four country samples. Table 5 presents the resulting mean values, separately for the intrapersonal in interpersonal factors and arranged by size. The highest mean value for the intrapersonal emotional competences was obtained for the Slovene sample, and the lowest mean values were obtained for the Czech and Croatian 
samples. The latent mean for the interpersonal emotional competences was the highest in the Croatian sample followed by the Indian sample, and it was the lowest in the Czech sample.

Table 5

Latent Mean Values for the Two IIECQ Factors by Country and Gender Groups

\begin{tabular}{|c|c|c|c|c|}
\hline & & & Latent mean & $\begin{array}{l}\text { Group } \\
\text { comparison }^{\#}\end{array}$ \\
\hline \multirow{9}{*}{$\begin{array}{l}\text { Intrapersonal emotional } \\
\text { skills and competences }\end{array}$} & Country & & & \\
\hline & CZE & Czech Republic & -.309 & \\
\hline & HRV & Croatia & -.236 & \\
\hline & RUS & Russia & -.205 & \\
\hline & IND & India & -.158 & \\
\hline & SVN & Slovenia & .000 & CZE, HRV \\
\hline & Gender & & & \\
\hline & $\mathrm{F}$ & Female & -.095 & \\
\hline & M & Male & .000 & \\
\hline \multirow{9}{*}{$\begin{array}{l}\text { Interpersonal emotional } \\
\text { skills and competences }\end{array}$} & Country & & & \\
\hline & CZE & Czech Republic & -.260 & \\
\hline & RUS & Russia & -.107 & \\
\hline & SVN & Slovenia & .000 & $\mathrm{CZE}$ \\
\hline & IND & India & .073 & CZE \\
\hline & HRV & Croatia & .166 & CZE, RUS \\
\hline & Gender & & & \\
\hline & $\mathrm{F}$ & Female & -.004 & \\
\hline & M & Male & .000 & \\
\hline
\end{tabular}

Note. ${ }^{\#}$ Groups with significantly lower mean.

Although measurement invariance allows us to compare latent means across groups, it should be stressed that our sampling procedure was not optimal; the samples were not representative and researchers from each country used their own social networks to collect the data. Consequently, some systematic factors could influence the result in each country, leading to a different ranking of countries. For example, female participants were overrepresented in the Slovene and the Croatian samples compared to the rest of the samples although, as further discussed below, our results also showed that the two gender groups did not differ in the emotional skills and competences measured. We should also take into account that all but one sample was from Central/East Europe and that large differences among countries were not expected. We could expect that Indian sample would be different from European samples given higher collectivism typical for this country (Ralston et al., 2011). However, East European countries are also not very individualistic, and hence small differences are not surprising. In the cross-cultural study of the ESCQ (Takšić 
et al., 2013) among 11 countries, only Japanese participants had lower results on the three subscales compared to participants from other countries.

We were also interested in gender differences. To compare gender groups, latent means for the two factors were set to zero in the male group and they were freely estimated in the female group. No significant differences were observed between men and women neither in the intrapersonal factor nor in the interpersonal factor (Table 5). Although previous studies with the original ESCQ (Takšić et al., 2018) or other EI questionnaires (e.g., Petrides \& Furnham, 2000) reported higher emotional competences for females, these differences were small. No gender differences were also reported in a meta-analysis of self-reported ability-based EI questionnaires (Joseph \& Newman, 2010).

\section{Construct Validity of the IIECQ}

To assess the construct validity of the IIECQ, correlations were examined between the IIECQ subscale scores and the measures of emotion regulation, personality, and well-being across countries and gender groups (Table 6). Across the five countries, the lowest and least significant correlations with the validity criteria were found for the Czech sample, whereas the highest correlations were observed for the Croatian sample, followed by the Russian and the Slovene samples. The correlations of the two gender groups with the validity criteria were of similar size.

The two emotion regulation strategies measured by the ERQ are reappraisal and suppression. Across four of the five countries and both genders, the two IIECQ subscales correlated positively with reappraisal. Although each of the two IIECQ subscales measures two of the three domains (emotion perception and emotion understanding) of the cascading model of emotional intelligence (Joseph \& Newman, 2010), and the ERQ is related to the third domain (emotion regulation), the three domains are interrelated, thus positive correlations of both IIECQ subscales with the reappraisal strategy of emotion regulation as an adaptive way of emotion regulation were expected.

On the other hand, emotion suppression is usually seen as a maladaptive emotion regulation strategy (Gross \& John, 2003; John \& Gross, 2004) and negative correlations could be expected with the emotional intelligence scales since the emotional knowledge allows an individual to use more adaptive emotional strategies. The intrapersonal subscale correlated negatively with emotion suppression in four countries and the female sample, so the results were in line with the expectations. The correlations of the interpersonal subscale with emotion suppression were weaker and more variable in different groups; mostly they were non-significant. However, a significant negative correlation was observed in the Slovene sample and a significant positive correlation was found in the Russian sample. Emotion regulation seems to be more culture-specific, compared to emotion perception and emotion knowledge (Shao, Doucet, \& Caruso, 2015), and the majority of previous studies regarding 
maladaptive aspects of emotion suppression were made in individualistic cultures (Gross \& John, 2003; John \& Gross, 2004). Later studies, using samples from collectivistic cultures, found that emotion suppression was not related to negative outcomes (Soto, Perez, Kim, Lee, \& Minnick, 2011). Similarly, in our study we did not find that perception and understanding of other`s emotions would be related to a lower suppression except in the Slovene sample; in the Russian sample, it was even related to a more frequent use of emotion suppression.

Table 6

Correlations between the IIECQ Subscales and the Measures of Emotion Regulation, Personality, and Well-Being by Country and Gender Groups

\begin{tabular}{|c|c|c|c|c|c|c|c|c|}
\hline & & Slovenia & India & Croatia & $\begin{array}{c}\text { Czech } \\
\text { Republic }\end{array}$ & Russia & Male & Female \\
\hline \multicolumn{9}{|c|}{ Intrapersonal emotional skills and competences } \\
\hline \multirow[t]{2}{*}{$\overline{\text { ERQ }}$} & Reappraisal & $.20^{* *}$ & $.34^{* * *}$ & $.23^{* * *}$ & .16 & $.25^{* *}$ & $.26^{* *}$ & $.20^{* *}$ \\
\hline & Suppression & $-.37^{* *}$ & $-.18^{*}$ & $-.40^{* * *}$ & $-.17^{*}$ & -.04 & -.10 & $-.29^{* * *}$ \\
\hline \multirow[t]{5}{*}{ BFI } & Extraversion & $.28^{* *}$ & $.24^{* *}$ & $.29^{* *}$ & $.34^{* *}$ & $.33^{* *}$ & $.21^{* *}$ & $.32^{* *}$ \\
\hline & Agreeableness & .10 & .13 & $.27^{* *}$ & .13 & $.12^{*}$ & .09 & $.16^{* *}$ \\
\hline & Conscientiousness & $.27^{* *}$ & $.21^{*}$ & $.33^{* *}$ & .09 & $.27^{* *}$ & $.32^{* *}$ & $.23^{* *}$ \\
\hline & Neuroticism & $-.29^{* * *}$ & $-.35^{* *}$ & $-.35^{* *}$ & $-.41^{* *}$ & $-.15^{*}$ & $-.23^{* *}$ & $-.30^{* *}$ \\
\hline & Openness & $.19^{* *}$ & .16 & $.19^{* *}$ & .10 & $.20^{* *}$ & $.21^{* *}$ & $.14^{* *}$ \\
\hline \multirow{3}{*}{$\begin{array}{l}\text { MHC- } \\
\text { SF }\end{array}$} & Emotional WB & $.32^{* *}$ & $.33^{* *}$ & $.42^{* *}$ & .15 & $.39^{* *}$ & $.29^{* *}$ & $.35^{* *}$ \\
\hline & Social WB & $.37^{* *}$ & $.36^{* *}$ & $.35^{* *}$ & .13 & $.33^{* *}$ & $.27^{* *}$ & $.36^{* *}$ \\
\hline & Psychological WB & $.47^{* *}$ & $.38^{* *}$ & $.51^{* *}$ & $.32^{* *}$ & $.43^{* *}$ & $.35^{* *}$ & $.46^{* *}$ \\
\hline \multicolumn{9}{|c|}{ Interpersonal emotional skills and competences } \\
\hline \multirow[t]{2}{*}{ ERQ } & Reappraisal & $.17^{*}$ & $.22^{* *}$ & .10 & $.40^{* * *}$ & $.37^{* *}$ & $.27^{* *}$ & $.27^{* * *}$ \\
\hline & Suppression & $-.31^{* *}$ & .04 & .03 & .07 & $.18^{* *}$ & .05 & .01 \\
\hline \multirow[t]{5}{*}{ BFI } & Extraversion & $.28^{* *}$ & .08 & .10 & $.20^{*}$ & $.31^{* *}$ & $.21^{* *}$ & $.20^{* *}$ \\
\hline & Agreeableness & .02 & .13 & .08 & $.22^{* *}$ & -.05 & .07 & .04 \\
\hline & Conscientiousness & $.23^{* *}$ & .05 & $.18^{* *}$ & .13 & $.22^{* *}$ & .10 & $.22^{* *}$ \\
\hline & Neuroticism & -.08 & -.03 & -.08 & -.16 & -.08 & $-.13^{*}$ & -.06 \\
\hline & Openness & $.28^{* *}$ & $.36^{* *}$ & $.35^{* *}$ & $.29^{* *}$ & $.23^{* *}$ & $.26^{* *}$ & $.28^{* *}$ \\
\hline \multirow{3}{*}{$\begin{array}{l}\text { MHC- } \\
\text { SF }\end{array}$} & Emotional WB & $.21^{* *}$ & .09 & $.18^{* *}$ & .03 & $.19^{* * *}$ & $.22^{* *}$ & $.14^{* *}$ \\
\hline & & & & & & & & \\
\hline & Psychological WB & $.31^{* *}$ & $.26^{* *}$ & $.20^{* * *}$ & $.24^{* *}$ & $.30^{* * *}$ & $.30^{* *}$ & $.28^{* *}$ \\
\hline
\end{tabular}

Note. ${ }^{*} p<.05 ;{ }^{* *} p<.01$.

The examination of the correlations of the IIECQ subscales with the basic personality traits revealed a somewhat stronger association of the intrapersonal subscale with personality compared to the interpersonal subscale. Before examining correlations in more detail, we must mention a lower reliability of some of the BFI subscales in one or more countries, which could be attributed to a relatively low number of items per subscale (considering that the shortened version of the BFI was 
used), so these correlations should be treated with caution. Personality traits most strongly associated with the intrapersonal subscale across all groups were extraversion and neuroticism; their correlations were in the opposite directions. Conscientiousness and openness were also correlated positively with the intrapersonal subscale in all groups but the Czech sample. Correlations between agreeableness and the intrapersonal subscale were weaker and significant only in the Croatian and the Russian samples and in the female sample. The interpersonal subscale was most strongly correlated with openness, with positive and significant correlations in all groups. Weaker and more variable correlations of the interpersonal subscale were observed with extraversion and conscientiousness. Correlations with agreeableness and neuroticism were close to zero in almost all groups. Insignificant correlations with agreeableness and neuroticism were found also in previous studies using ESCQ (except for the MR subscale, which has no equivalent in IIECQ) (Takšić, 2001; Takšić et al., 2018). In a meta-analysis (Joseph \& Newman, 2010), the sample-size weighted mean correlations between the self-reported ability EI measures and extraversion, agreeableness, conscientiousness neuroticism, and openness were $.27, .26, .32, .34, .24$, respectively. Therefore, the pattern of correlations between personality and the ESCQ and the IIECQ are somewhat specific compared to other self-rated ability EI measures.

Finally, correlations of the IIECQ subscales with the emotional, social, and psychological components of well-being were positive and they were slightly higher for the intrapersonal subscale, but generally significant also for the interpersonal subscale. The highest correlations across all groups were observed with the psychological well-being. Several studies showed significant correlations between emotional intelligence and subjective well-being (e.g., Avsec et al., 2009; Gallagher \& Vella-Broderick, 2008; Landa, Martos, \& López-Zafra, 2010). Individuals who perceive and understand theirs and others emotions tend to behave more rationally when confronted with problems, perceive everyday troubles as less stressful, and consequently experience higher subjective well-being (Bar-On, 2000).

\section{Conclusion}

The main issue of the present study was to examine psychometric properties of the Intrapersonal and Interpersonal emotional competences questionnaire (IIECQ) by analysing its factor structure and measurement invariance across countries and gender groups. Examining measurement invariance provides a valuable insight into similarity and dissimilarity of perception of the construct across different groups of participants.

The hypothesized two-factor structure of the IIECQ with factors comprising intrapersonal and interpersonal emotional competences, respectively, was confirmed across five countries and both gender groups, although some item residual 
covariances had to be estimated freely to ensure an adequate fit of the models. Measurement invariance of the IIECQ was investigated across five countries. Our results revealed that configural and metric invariances held across countries, but scalar invariance was partial with three items having varying intercepts in different countries. According to Steenkamp and Baumgartner (1998), at least two invariant items per scale are required for valid factor mean comparisons across groups. With this condition satisfied, latent scores of the two IIECQ factors were compared between the five countries. The obtained differences were small. Intrapersonal emotional competences were lower in the Czech Republic and Croatia, compared to Slovenia, which had the highest latent mean value for this factor. Participants from the Czech Republic had the lowest level of interpersonal emotional competences, whereas Croatians had the highest level of these skills. Nevertheless, the non-optimal sampling procedure across countries should be taken into consideration when interpreting these results. Full measurement invariance was confirmed across gender groups. The comparison of factor means revealed no differences between men and women in the two factors of emotional competences. Our results also indicated good construct validity of the IIECQ in terms of the relationships with the personality traits, subjective well-being and emotion regulation. Overall, our results suggest that the IIECQ measures emotional competences in the same way across the five countries investigated as well as across gender.

Our study has some limitations worth noting. The construct validity of the IIECQ should be examined in much more detail. Although all the items of the original ESCQ were designed according to the Mayer-Salovey model of EI (Mayer \& Salovey, 1997), only 45 of the initial 300 items were retained in the ESCQ based on the exploratory factor analysis results (Takšić, 1998, 2001). In this study, we additionally selected only 12 items from the ESCQ on the theoretical account regarding the self and other distinction, but the distinction between the first and the second branch of the Mayer-Salovey model (Mayer \& Salovey, 1997) or the cascading model (Joseph \& Newman, 2010; perception and understanding) was not considered. In future studies, correlations with all four branches of the model should be examined to contextualize intrapersonal and interpersonal emotional competences scales in the emotional competence space.

One problematic issue of the study concerns the convenience sampling of participants, which resulted in a disproportional share of male and female participants that were all of similar age, thus limiting generalizability of our results and their interpretation. Possibly, the cross-cultural differences would be larger if other than students were included in the sample. Samples from some of the countries were relatively small and should be enhanced, both in terms of their size and heterogeneity, for more robust conclusions. Although our results indicate that the IIECQ scores can be meaningfully compared across countries, only East/Middle European countries and India were included in the present study. Samples from West European and Asian countries were also collected but were not large enough to 
include them in the analysis. Future studies should examine measurement invariance of the IIECQ in other national samples as well. Self-selection of the participants could represent another limitation that could affect counties' mean levels of emotional skills and competences.

Overall, our findings supported the hypothesized two-factor structure of the IIECQ. Measurement invariance was confirmed across five countries included in the study (the exception being noninvariant intercepts of three items) as well as across both gender groups. IIECQ overcomes several shortcomings of the original ESCQ, with one of the benefits also being a reduced length of the scale. A further examination of measurement invariance of the IIECQ across various countries could advance our understanding of cross-cultural differences in emotional competences as well as in antecedents and consequences related to it.

\section{References}

Averill, J. R., \& Thomas-Knowles, C. (1991). Emotional creativity. In K. T. Strongman (Ed.), International review of studies on emotions (Vol. 1, pp. 269-299). London: Wiley.

Avsec, A. (2005, July). Emotional Skills and Competence Questionnaire: Reliability and validity of a Slovene version. In V. Takšić (Chair), Cross-cultural validation of Emotional Skills and Competence Questionnaire (ESCQ). Symposium conducted at the $9^{\text {th }}$ European Congress of Psychology, Granada, Spain.

Avsec, A., Masnec, P., \& Komidar, L. (2009). Personality traits and emotional intelligence as predictors of teachers' psychological well-being. Horizons of Psychology, 18(3), 73-86.

Avsec, A., Takšić, V., \& Mohorić, T. (2009). The relationship of trait emotional intelligence with the Big Five in Croatian and Slovene university student sample. Horizons of Psychology, 18, 99-110.

Bar-On, R. (2000). Emotional and social intelligence: Insights from the Emotional Quotient Inventory. In R. Bar-On \& J. D. A. Parker (Eds.), Handbook of emotional intelligence: Theory, development, assessment, and application at home, school and in the workplace (pp. 363-388). San Francisco: Jossey-Bass.

Bar-On, R. (2002). Bar-On Emotional Quotient Inventory: Short (EQ-i: S): Technical manual. Canada: Multi-Health Systems Inc.

Bentler, P. M. (1990). Comparative fit indexes in structural models. Psychological Bulletin, 107(2), 238-246.

Binet, A. (1905/1916). New methods for the diagnosis of the intellectual level of subnormals. In E. S. Kite (transl.), The development of intelligence in children (pp. 1-90). Vineland, NJ: Publications of the Training School at Vineland.

Browne, M. W., \& Cudeck, R. (1993). Alternative ways of assessing model fit. Sage Focus Editions, 154, 136.

Byrne, B. M. (2008). Testing for multigroup equivalence of a measuring instrument: A walk through the process. Psicothema, 20, 872-882. 
Byrne, B. M. (2013). Structural equation modeling with Mplus: Basic concepts, applications, and programming. New York: Routledge.

Byrne, B. M., Shavelson, R. J., \& Muthén, B. (1989). Testing for the equivalence of factor covariance and mean structures: The issue of partial measurement invariance. Psychological Bulletin, 105, 456-466.

Chen, F. F. (2007). Sensitivity of goodness of fit indexes to lack of measurement invariance. Structural Equation Modeling: A Multidisciplinary Journal, 14(3), 464-504.

Extremera, N., \& Fernández-Berrocal, P. (2005, July). Emotional Skills and Competence Questionnaire (ESCQ): Adaptation to Spanish, reliability and its relationship with wellbeing indexes. In V. Takšić (Chair), Cross-cultural validation of Emotional Skills and Competence Questionnaire (ESCQ). Symposium conducted at the $9^{\text {th }}$ European Congress of Psychology, Granada, Spain.

Faria, L., \& Lima Santos, N. (2005, July). Adaptation of the Emotional Skills and Competence Questionnaire (ESCQ) to the Portuguese context. In V. Takšić (Chair), Cross-cultural validation of Emotional Skills and Competence Questionnaire (ESCQ). Symposium conducted at the $9^{\text {th }}$ European Congress of Psychology, Granada, Spain.

Faria, L., Lima Santos, N., Takšić, V., Räty, H., Molander, B., Holmström, S., \& Toyota, H. (2006). Cross-cultural validation of the Emotional Skills and Competence Questionnaire (ESCQ). Psicologia, 20, 95-127.

Gallagher, E. N., \& Vella-Broderick, D. A. (2008). Social support and emotional intelligence as predictors of subjective well-being. Personality and Individual Differences, 44, 15511561.

Gardner, H. (1983). Frames of mind: The theory of multiple intelligences. New York: Basic Books.

Goleman, D. (1995). Emotional intelligence. New York: Bantam Books.

Gross, J. J., \& John, O. P. (2003). Individual differences in two emotion regulation processes: Implications for affect, relationships, and wellbeing. Journal of Personality and Social Psychology, 85, 348-362.

Haga, S. M., Kraft, P., \& Corby, E. (2009). Emotion regulation: Antecedents and well-being outcomes of cognitive reappraisal and expressive suppression in cross-cultural samples. Journal of Happiness Studies, 10(3), 271-291.

Hu, L., \& Bentler, P. M. (1999). Cutoff criteria for fit indexes in covariance structure analysis: Conventional criteria versus new alternatives. Structural Equation Modeling, 6(1), 155. https://doi.org/10.1080/10705519909540118

John, O. P., \& Gross, J. J. (2004). Healthy and unhealthy emotion regulation: Personality processes, individual differences, and lifespan development. Journal of Personality, 72, 1301-1334.

Joseph, D. L., \& Newman, D. A. (2010). Emotional intelligence: An integrative meta-analysis and cascading model. Journal of Applied Psychology, 95(1), 54-78.

Keyes, C. L. M. (2005). Mental illness and/or mental health? Investigating axioms of the complete state model of health. Journal of Consulting and Clinical Psychology, 73, 539548. 
Avsec, A., Belasheva, I., Cenek, J., Khan, A., Mohorić, T., Takšić, V., Zager Kocjan, G.: Measurement Invariance of the ESCQ-R

Kovaleva, A., Beierlein, C., Kemper, C. J., \& Rammstedt, B. (2013). Psychometric properties of the BFI-K: A cross-validation study. The International Journal of Educational and Psychological Assessment, 13(1), 34-50.

Landa, J. M. A., Martos, M. P., \& López-Zafra, E. (2010). Emotional intelligence and personality traits as predictors of psychological well-being in Spanish undergraduates. Social Behavior and Personality: An International Journal, 38(6), 783-794.

Lapierre, S. (2008, July). Emotional intelligence and well-being in old age. Paper presented at $4^{\text {th }}$ European Conference on Positive Psychology, Opatija, Croatia.

Legree, P. J., Psotka, J., Robbins, J., Roberts, R. D., Putka, D. J., \& Mullins, H. M. (2014). Profile similarity metrics as an alternate framework to score rating-based tests: MSCEIT reanalyses. Intelligence, 47, 159-174.

MacCann, C., Joseph, D. L., Newman, D. A., \& Roberts, R. D. (2014). Emotional intelligence is a second-stratum factor of intelligence: Evidence from hierarchical and bifactor models. Emotion, 14, 358-374.

MacCann, C., \& Roberts, R. D. (2008). New paradigms for assessing emotional intelligence: Theory and data. Emotions, 8, 540-551.

Mayer, J. D., Caruso, D. R., \& Salovey, P. (2016). The ability model of emotional intelligence: Principles and updates. Emotion Review, 8, 290-300.

Mayer, J. D., \& Salovey, P. (1995). Emotional intelligence and the construction and regulation of feelings. Applied and Preventive Psychology, 4, 197-208.

Mayer, J. D., \& Salovey, P. (1997). What is emotional intelligence? In P. Salovey \& D. Sluyter (Eds.), Emotional development and emotional intelligence: Implications for educators (pp. 3-31). New York: Basic Books.

Mayer, J. D., \& Stevens, A. A. (1994). An emerging understanding of the reflective (meta) experience of mood. Journal of Research in Personality, 28, 351-373.

Mayer, J. D., Caruso, R. D., Ziegler, E., \& Dreyden, J. I. (1989). Intelligence and intelligencerelated personality traits. Intelligence, 13, 119-133.

Melka, S. E., Lancaster, S. L., Bryant, A. R., \& Rodriguez, B. F. (2011). Confirmatory factor and measurement invariance analyses of the emotion regulation questionnaire. Journal of Clinical Psychology, 67(12), 1283-1293.

Mikulić, I. M. (2008, July). Cross-cultural validation of Emotional Skills and Competence Questionnaire: Assessing structural equivalence of adapted ESCQ for Argentina. In V. Takšić (Chair), Cross cultural validation of various measures of emotional intelligence. Symposium conducted at the $29^{\text {th }}$ International Congress of Psychology, Berlin, Germany.

Molander, B., Holmström, S., \& Jansson, J. (2005, July). ESCQ-45 as related to self-rated job stress and health. In V. Takšić (Chair), Cross-cultural validation of Emotional Skills and Competence Questionnaire (ESCQ). Symposium conducted at the $9^{\text {th }}$ European Congress of Psychology, Granada, Spain.

Muthén, L. K., \& Muthén, B. O. (1998-2018). Mplus user's guide (8th ed.). Los Angeles: Muthén \& Muthén. 
O’Connor, P. J., Hill, A., Kaya, M., \& Martin, B. (2019). The measurement of emotional intelligence: A critical review of the literature and recommendations for researchers and practitioners. Frontiers in Psychology, 10, 1116.

Petrides, K. V., \& Furnham, A. (2000). Gender differences in measured and self-estimated trait emotional intelligence. Sex Roles, 42, 449-461.

Petrides, K. V., Pita, R., \& Kokkinaki, F. (2007). The location of trait emotional intelligence in personality factor space. British Journal of Psychology, 98, 273-289.

Petrides, K. V., Sangareau, Y., Furnham, A., \& Frederickson, N. (2006). Trait emotional intelligence and children's peer relations at school. Social Development, 15, 537-547.

Ralston, D. A., Egri, C. P., Reynaud, E., Srinivasan, N., Furrer, O., Brock, D., \& Wallace, A. (2011). A twenty-first century assessment of values across the global workforce. Journal of Business Ethics, 104, 1. https://doi.org/10.1007/s10551-011-0835-8

Räty, H. (2005, July). Perceived emotional competence and self-concept. In V. Takšić (Chair), Cross-cultural validation of Emotional Skills and Competence Questionnaire (ESCQ). Symposium conducted at the $9^{\text {th }}$ European Congress of Psychology, Granada, Spain.

Rice, S. M., Treeby, M. S., Gersh, E., Ogrodniczuk, J. S., \& Kealy, D. (2018). The emotion regulation questionnaire: ERQ-9 factor structure and measurement invariance in Australian and Canadian community samples. TPM Testing, Psychometrics, Methodology in Applied Psychology, 25(3), 369-378.

Saklofske, D. H, Austin, E. J., \& Minski, P. S. (2003). Factor structure and validity of a trait emotional intelligence measure. Personality and Individual Differences, 34, 707-721.

Salovey, P., \& Mayer, J. D. (1990). Emotional intelligence. Imagination, Cognition, and Personality, 9(3), 185-211.

Salovey, P., Mayer, J. D., Goldman, S. L., Turvey, C., \& Palfai, T. P. (1995). Emotional attention, clarity, and repair: Exploring emotional intelligence using the Trait MetaMood Scale. In J. W. Pennebaker (Ed.), Emotion, disclosure, \& health (pp. 125-154). Washington: American Psychological Association.

Sánchez-Álvarez, N., Extremera, N., \& Fernández-Berrocal, P. (2015). The relation between emotional intelligence and subjective well-being: A meta-analytic investigation. The Journal of Positive Psychology, 11, 276-285.

Shao, B., Doucet, L., \& Caruso, D. R. (2015). Universality versus cultural specificity of three emotion domains: Some evidence based on the cascading model of emotional intelligence. Journal of Cross-Cultural Psychology, 46(2), 229-251.

Soto, J. A., Perez, C. R., Kim, Y. H., Lee, E. A., \& Minnick, M. R. (2011). Is expressive suppression always associated with poorer psychological functioning? A cross-cultural comparison between European Americans and Hong Kong Chinese. Emotion, 11(6), 1450-1455.

Steenkamp, J. B. E., \& Baumgartner, H. (1998). Assessing measurement invariance in crossnational consumer research. Journal of Consumer Research, 25, 78-90. 
Avsec, A., Belasheva, I., Cenek, J., Khan, A., Mohorić, T., Takšić, V., Zager Kocjan, G.: Measurement Invariance of the ESCQ-R

Takšić, V. (1998). Validacija konstrukta emocionalne inteligencije. [Validation of the Emotional Intelligence Construct]. (Unpublished doctoral dissertation.) Faculty of Humanities and Social Sciences, University of Zagreb, Zagreb.

Takšić, V. (2001). Upitnici emocionalne kompetentnosti (inteligencije). [Emotional competence (intelligence) questionnaires]. In K. Lacković-Grgin \& Z. Penezić (Eds.), Zbirka psihologijskih mjernih instrumenata. [The collection of psychological instruments.] (pp. 27-41). Zadar: University of Zadar.

Takšić, V. (2002, October). The importance of emotional intelligence (competence) in positive psychology. Paper presented at the $1^{\text {st }}$ International Positive Psychology Summit, Washington, DC.

Takšić, V. (July, 2005). Basic psychometric properties of Emotional Skills and Competence Questionnaire (ESCQ) in Croatian samples. In V. Takšić (Chair), Cross-cultural validation of Emotional Skills and Competence Questionnaire (ESCQ). Symposium conducted at the $9^{\text {th }}$ European Congress of Psychology, Granada, Spain.

Takšić, V., Bradić, S, \& Žauhar, V. (2013). Prikaz metoda za procjenu kroskulturalne ekvivalentnosti na primjeru Upitnika emocionalne kompetentnosti [Overview of some cross-cultural equivalence procedures performed on the Emotional Skills and Competence Questionnaire]. Primenjena psihologija, 6, 101-120.

Takšić, V., Mohorić, T., \& Holmström, S. (2018). Cross-cultural studies of trait emotional intelligence using the Emotional Skills and Competence Questionnaire. In M. C. PerezFuentes, M. M. Molero Jurado, \& J. J. Gazquez Linares (Eds.), Emotional intelligence: Perceptions, interpretations, and attitudes (pp. 29-64). New York: Nova Science Publishers, Inc.

Takšić, V., Mohorić, T., \& Duran, M. (2009). Emotional Skills and Competence Questionnaire (ESCQ) as a self-report measure of emotional intelligence. Horizons of Psychology, 18, 7-21.

Toyota, H., Morita, T., \& Takšić, V. (2007). Development of a Japanese version of the emotional skills and competence questionnaire. Perceptual and Motor Skills, 105, 469476.

van de Vijver, F., \& Hambleton, R. K. (1996) Translating tests: Some practical guidelines. European Psychologist, 1, 89-99.

$\mathrm{Xu}, \mathrm{Q}$. (2008, July). Validation of the emotion skills and competence questionnaire in Chinese setting. In V. Takšić (Chair), Cross cultural validation of various measures of emotional intelligence, $29^{\text {th }}$ International Congress of Psychology, Berlin, Germany.

Żemojtel, P. M., Piotrowski, J. P., Osin, E. N., Cieciuch, J., Adams, B. G., Ardi, R., ... Maltby, J. (2018). The mental health continuum- short form: The structure and application for cross- cultural studies - a 38 nation study. Journal of Clinical Psychology, 74(6), 10341052 .

Received: September 22, 2019 


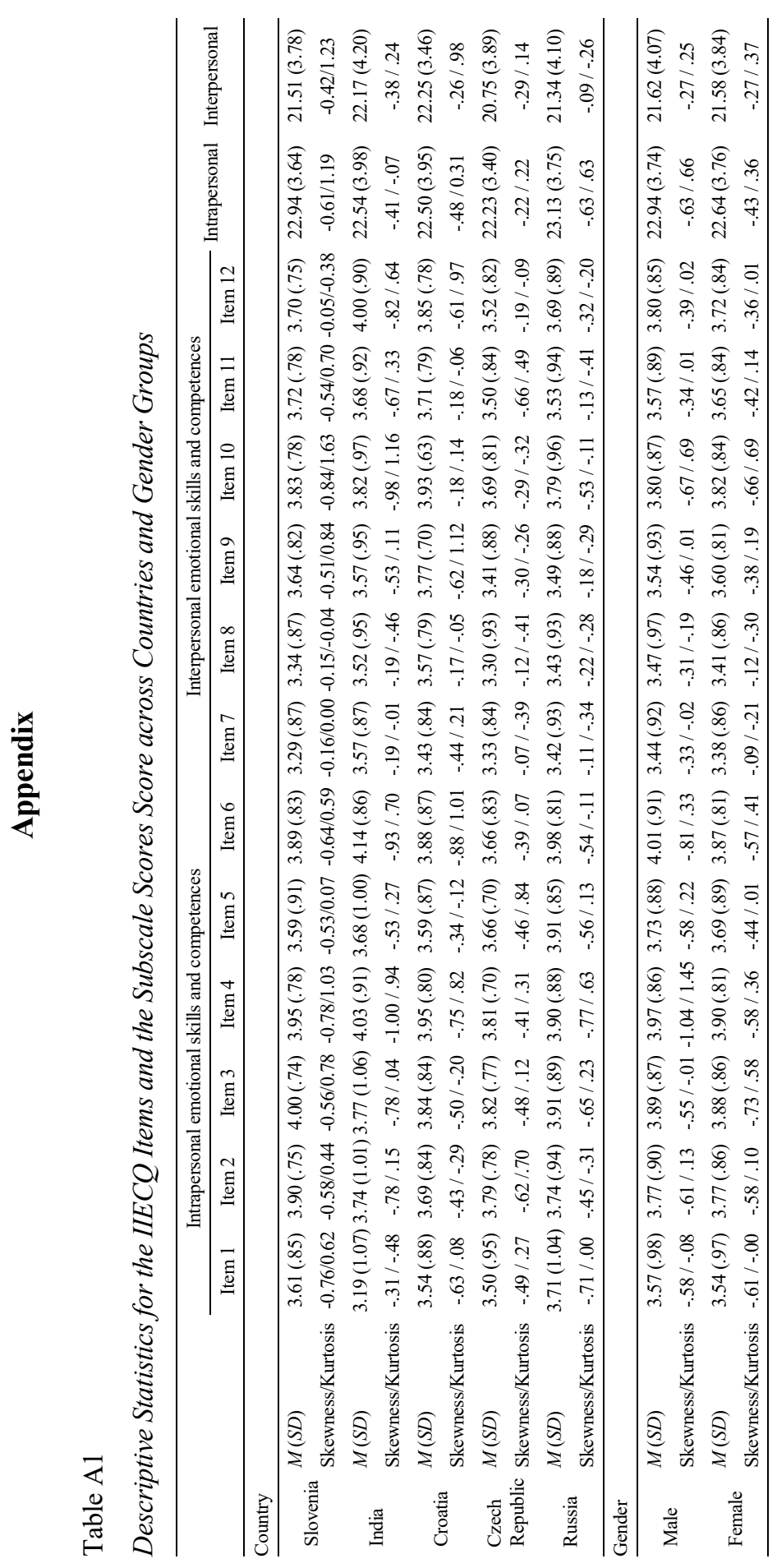


Avsec, A., Belasheva, I., Cenek, J., Khan, A., Mohorić, T., Takšić, V., Zager Kocjan, G.: Measurement Invariance of the ESCQ-R

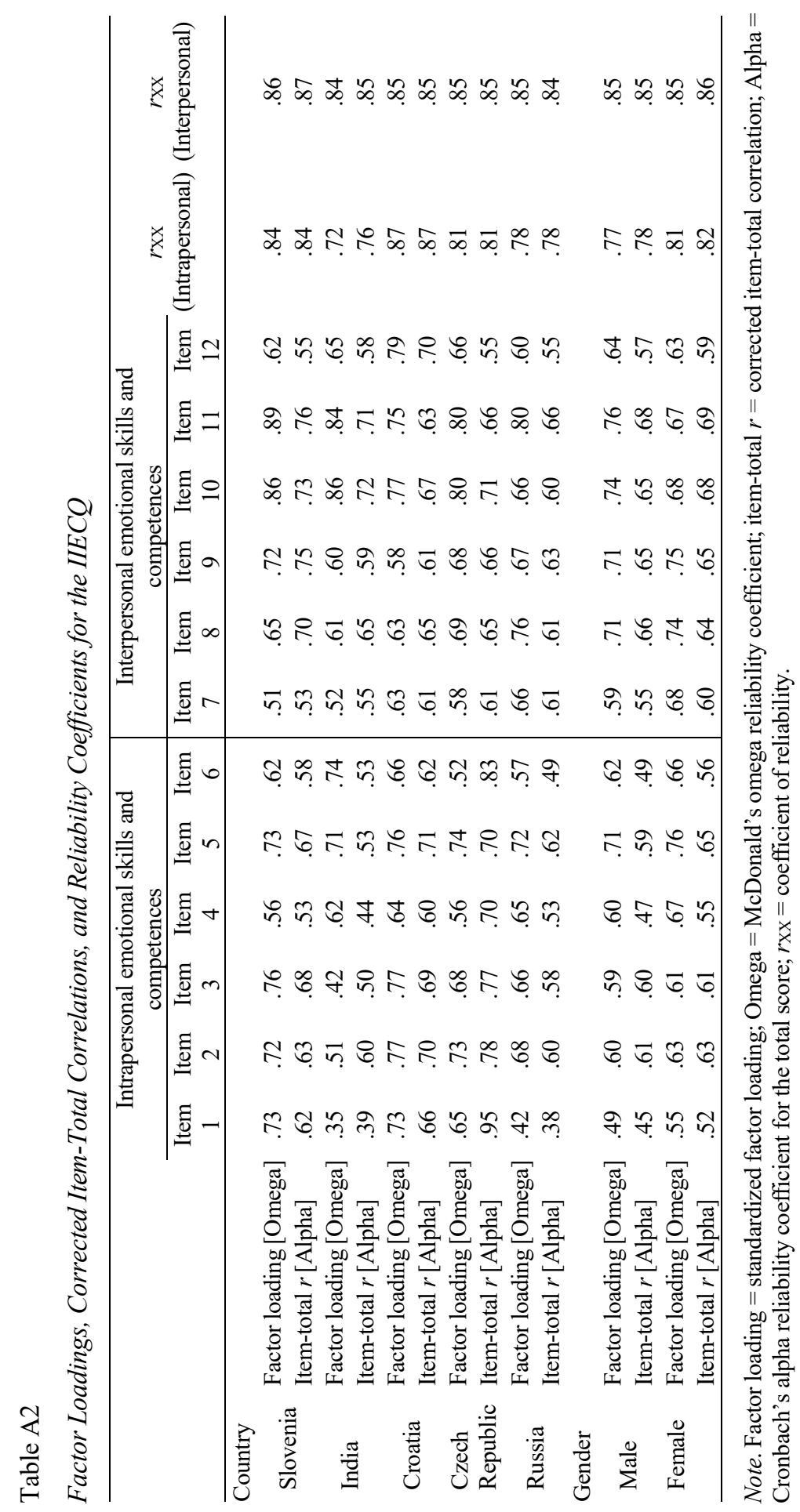


Table A3

Descriptive Statistics for the ERQ, BFI, and MHC-SF across Countries

\begin{tabular}{|c|c|c|c|c|c|c|c|}
\hline & Scale & & Slovenia & India & Croatia & $\begin{array}{c}\text { Czech } \\
\text { Republic }\end{array}$ & Russia \\
\hline \multirow[t]{6}{*}{$\overline{\text { ERQ }}$} & Reappraisal & $M$ & 27.5 & 30.5 & 28.8 & 28.3 & 27.7 \\
\hline & & $S D$ & 6.8 & 6.1 & 6.5 & 5.8 & 7.0 \\
\hline & & Alpha & .82 & .79 & .84 & .72 & .83 \\
\hline & Suppression & $M$ & 13.7 & 17.3 & 15.5 & 14.2 & 16.6 \\
\hline & & $S D$ & 5.0 & 5.4 & 4.7 & 4.9 & 5.0 \\
\hline & & Alpha & .76 & .72 & .73 & .75 & .74 \\
\hline \multirow[t]{15}{*}{ BFI } & Extraversion & $M$ & 13.1 & 12.8 & 12.8 & 14.1 & 12.5 \\
\hline & & $S D$ & 3.4 & 2.9 & 3.1 & 3.2 & 3.3 \\
\hline & & Alpha & .72 & .65 & .72 & .75 & .63 \\
\hline & Agreeableness & $M$ & 13.5 & 13.5 & 12.2 & 13.4 & 11.6 \\
\hline & & $S D$ & 3.0 & 2.5 & 2.9 & 2.9 & 3.1 \\
\hline & & Alpha & .61 & .33 & .56 & .54 & .51 \\
\hline & Conscientiousness & $M$ & 14.4 & 13.9 & 14.2 & 13.1 & 14.4 \\
\hline & & $S D$ & 2.7 & 2.4 & 2.8 & 2.6 & 2.7 \\
\hline & & Alpha & .70 & .53 & .73 & .56 & .60 \\
\hline & Neuroticism & $M$ & 12.3 & 11.5 & 12.2 & 11.8 & 12.3 \\
\hline & & $S D$ & 3.8 & 3.3 & 3.6 & 3.5 & 3.4 \\
\hline & & Alpha & .81 & .74 & .77 & .76 & .66 \\
\hline & Openness & $M$ & 19.6 & 19.8 & 20.0 & 18.2 & 18.0 \\
\hline & & $S D$ & 3.7 & 3.0 & 3.0 & 3.2 & 3.2 \\
\hline & & Alpha & .75 & .69 & .68 & .67 & .56 \\
\hline \multirow[t]{9}{*}{ MHC-SF } & Emotional WB & $M$ & 12.6 & 13.2 & 13.8 & 12.8 & 13.0 \\
\hline & & $S D$ & 3.2 & 3.0 & 3.0 & 2.7 & 3.3 \\
\hline & & Alpha & .88 & .81 & .87 & .65 & .85 \\
\hline & Social WB & $M$ & 16.3 & 18.0 & 15.7 & 15.6 & 18.0 \\
\hline & & $S D$ & 5.7 & 5.8 & 5.3 & 5.1 & 5.7 \\
\hline & & Alpha & .83 & .81 & .78 & .76 & .79 \\
\hline & Psychological WB & $M$ & 24.3 & 26.4 & 26.2 & 22.7 & 25.9 \\
\hline & & $S D$ & 7.2 & 6.2 & 5.8 & 5.6 & 6.9 \\
\hline & & Alpha & .90 & .86 & .84 & .78 & .89 \\
\hline
\end{tabular}

